\title{
THE
}

\section{Look Good When You're Googled: Creating and Optimizing Your Digital Identity}

Amanda Izenstark

University of Rhode Island, amanda@uri.edu

Follow this and additional works at: https://digitalcommons.uri.edu/lib_ps_pubs

The University of Rhode Island Faculty have made this article openly available.

Please let us know how Open Access to this research benefits you.

This is a pre-publication author manuscript of the final, published article.

Terms of Use

This article is made available under the terms and conditions applicable towards Open Access

Policy Articles, as set forth in our Terms of Use.

\section{Citation/Publisher Attribution}

Izenstark, A. (2014). Look good when you're Googled: Creating and optimizing your digital identity. Library Hi Tech News, 31(9), 14-16.

Available at: http://dx.doi.org/10.1108/LHTN-07-2014-0061 


\title{
Look Good When You're Googled: Creating and Optimizing Your Digital Identity
}

Amanda Izenstark

University Libraries, University of Rhode Island

amanda@uri.edu

Amanda Izenstark (amanda@uri.edu) is Reference \& Instructional Design Librarian at the University Libraries, University of Rhode Island, Kingston, RI, USA.

\begin{abstract}
Purpose: This paper describes techniques librarians can use to enhance their online presence so that students, patrons, researchers, and prospective employers can locate them easily. It is an extension of a presentation given at the Association of College and Research Libraries New England Chapter Annual Conference held in Worcester, MA on May 9, 2014.

Design/methodology/approach: The presentation focused on a number of established and emerging tools to share professional contact information and professional output, such as Google, Google+, Twitter, Linkedln, SlideShare, and ImpactStory, among others.
\end{abstract}

Findings: The audience of library faculty and staff from across the Northeastern United States examined the results that appeared when they searched for themselves in major search engines (Google, Bing, and DuckDuckGo) and learned strategies and tools for optimizing the results that come up when others search for their contact information.

Practical implications: Librarians who focus on enhancing their professional profiles online make it easier for constituents to get assistance with research questions, they can make their value and the institution's value more visible, and facilitate the sharing of information in a field that looks to other institutions and individuals for inspiration for new programs and innovations.

Originality/value: While many of these tools are used in the business world to build and cultivate networks and seek employment, even steadily employed librarians can use these tools to make their expertise available to researchers at their institutions and beyond.

Keywords: social media, librarians, digital identity management

Article Classification: Research paper

\section{Look Good When You're Googled: Creating and Optimizing Your Digital Identity}

\section{Amanda Izenstark}

\section{Introduction}

Librarians are often public figures: they help patrons in person and online, work at service points in libraries, serve on campus and local committees, and provide outreach to potential patrons. In academic libraries where there might be an emphasis on personalized research help, students may need to contact the librarian they've met in a course for additional assistance, and turn to Google to locate contact information. At the same time, new and experienced librarians from every library type who are looking for new job opportunities may want to consider how they 
appear when potential employers or human resources staff do a basic web search for the name of the candidate they're about to bring in for an interview. This raises questions of what information to make available, what to keep private, and how to present a digital identity that is both easy to locate and appropriately private.

\section{First, Google (and Bing and DuckDuckGo) Thyself}

Before creating or adjusting a digital identity, it is a good practice to see what information is already available. Using Google (www.google.com), Bing (www.bing.com), and DuckDuckGo (www.duckduckgo.com) to search for one's own name one way to see what information is readily and easily available. These three tools use different search algorithms and return different results even given the same query. Other search tools may also be useful for assessing the information that is already available online.

It's important to do the same searches in various tools from other computers as well. Search engines frequently customize results based on whether or not a searcher is logged in to connected accounts, the searcher's location, and so on. For a broader perspective and to mimic the search results others might find, this can be an important step.

Determine whether it was easy to find contact information and whether the overall results seem satisfactory. Do the results project the professional image and level of accessibility that correspond with one's job roles?

\section{When Multiple People Share the Same Name}

Names may or may not be unique. For those with names shared by a number of other people, using middle names or initials is a first step to help disambiguate an individual. It can also be useful to develop and use the same tagline everywhere possible, and consistently include pertinent information that patrons might search for, such as "librarian," institution, and geographic location. For example, a student who encounters (fictional) librarian Jamie Doe during a class session at (fictional) Giant State University might later search for librarian Jamie Giant State or Jamie Giant State Library in order to locate ways to get help after the information session. In addition to enhancing one's findability, taglines are also a simple way to develop a personal brand.

\section{Public vs Personal}

Some librarians might find that too much personal information is available via search engines, and professional information seems hidden. To remedy this, evaluate the privacy settings on existing social media accounts, and consider strictly limiting the individuals that are able to see content and posts. It may be worth setting up new social media profiles and separating the professional from the personal. Separate accounts by using separate professional and personal email addresses wherever possible. While Facebook requires users to enter their real name, most other social media tools including Google+, Twitter, Tumblr, and more do not. This means it's easy to have a professional blog, Twitter profile, and Tumblr account under one's real name, but have a personal blog, Twitter profile, and Tumblr account under a nickname or even a pseudonym. 
No matter what level of sharing one opts for, it's is important to also consider what may be revealed by the geographic information that some social media tools also share. For example, someone posting to Twitter under a common name can be easily identified if the location sharing in Twitter is turned on.

Keep in mind that patrons, hiring committees, and other librarians do not expect everyone to be emotionless robots online. It is fine to show relevant interests and one's unique personality in posts on social media.

\section{Tools for Building and Optimizing One's Digital Identity}

\section{Facebook}

Facebook (www.facebook.com) offers a plethora of options for sharing information and connecting with others. Joining groups and following relevant pages helps create links between people, institutions, organizations, committees, and more. However, many Facebook users experience what researcher danah boyd describes as "context collapse": "when people are forced to grapple simultaneously with otherwise unrelated social contexts that are rooted in different norms and seemingly demand different social responses" (boyd, 2014, p. 31). Because of Facebook's emphasis on users having one account for all contexts, it is worth considering how and when to use it as a public digital identity tool.

\section{Twitter}

Unlike Facebook, Twitter (www.twitter.com) freely allows the use of real names as well as nicknames and pseudonyms, making it far easier to cultivate separate personal and professional accounts. In addition, the widespread use of Twitter as a backchannel during conferences makes it an even better tool for connecting with librarians in similar roles and for staying up-to-date on developments presented at conferences.

\section{SlideShare and Prezi}

These two presentation sharing tools make it easy to share work with a wider audience, and can be linked to other social media accounts. SildeShare (www.slideshare.com) is ideal for sharing PowerPoint and Keynote-style presentations, while Prezi (www.prezi.com) is a presentation creation tool that includes motion effects that can highlight specific points. Using these tools to share output can attract viewers, and help complete a portfolio of work.

\section{Linkedln}

While it may not seem intuitive to use a for-profit business oriented networking tool as a way for non-profit and educational institution employees to connect with others, many librarians use Linkedln (www.linkedin.com) to keep in touch with classmates from graduate school, committee members from across the country, current and former coworkers, and connect with potential future colleagues. At the most basic level, having a profile on Linkedln can allow others to see one's current work and projects. A more complete profile can send viewers to presentations hosted on SlideShare, Google Drive, Prezi, and other sites, as well as to articles and other written materials. While contact information for individuals with Linkedln profiles does not appear to the general public, once someone has logged in, they can contact the profiled individual.

Website Builders: Google Sites, WordPress, SquareSpace, Wix, etc. For some librarians, creating one's own website as a single point of reference to social media profiles, online presentations, resumes, and professional contact information is useful and 
important. Depending on the expected amount of traffic, one's technical skills, and one's budget, these four recommendations can be a starting point. Google Sites (sites.google.com) is part of the Google suite of applications, and Gmail users automatically have access to this basic website building tool. WordPress (www.wordpress.com) offers free basic blogging and website hosting; additional features and customization are available for a fee. SquareSpace (www.squarespace.com) and Wix (www.wix.com) are general website building platforms with various subscription plans to accommodate small budgets and bandwidth expectations.

\section{Special Considerations for Those In (Or Planning Careers In) Academic Libraries}

If an academic career is a reality or an aspiration, it's worth considering these tools specifically designed for academic researchers.

\section{Google Scholar Citations}

Google Scholar Citations (scholar.google.com/citations) profiles are available to those who have materials listed in Google Scholar. This provides a simple online profile displaying published materials and can be linked to an institutional email address for verification. It does not provide any typically social aspects aside from linking to co-authors, but it is a clean and clear way to display articles, book chapters, and other publications. Although the profiles can be kept private, public access to the profile makes it easy for others to discover one's work.

\section{ImpactStory}

ImpactStory (impactstory.org) does not host publications, but it is a profile tool that connects publications, presentations, datasets, and code to the author's profile, and measures the views, downloads, saves, Tweets, and other uses of one's output. It connects to SlideShare, GitHub (www.github.com), FigShare (www.figshare.com), and other places that researchers may post their materials, as well as citation managers where others may be keeping track of that information.

Academic Social Networks: Academia.edu and ResearchGate These two resources offer similar functionality in that they allow users to create profiles that link to publications they've authored or co-authored, and users can connect with researchers in similar areas and at the same institution. In addition to providing contact information and the ability to link to publications, Academia.edu (academia.edu) allows users to embed badges linking to Skype and other social media profiles. ResearchGate (researchgate.net) allows users to upload papers as well as link to them, which facilitates information sharing and increases visibility of one's work.

\section{Citation Managers with a Social Aspect: Zotero and Mendeley}

Setting up an account on Zotero (www.zotero.org) or Mendeley (www.mendeley.com) has benefits for both the account holder and the author. The basic use - saving citations and generating bibliographies - is very good, but they provide additional levels of functionality. Both offer options to create a public profile where users can share bibliographies, but when an author's article is saved to one of these tools, it increases the visibility of the item. ImpactStory, for example, displays statistics on how often an article has been saved by researchers who use Mendeley.

Digital Object Identifiers for People: ORCID iD and ResearcherID ORCID (orcid.org) and ResearcherID (www.researcherid.com) provide unique identifying numbers to qualifying researchers after they register on the site. These ID numbers help reduce 
confusion between individuals with the same name, and some publishers also use these identification numbers to make it easy to access an author's output. Additionally, the numbers can be used in other places (such as ImpactStory) to easily build a profile and import publication and citation information.

\section{Conclusion}

While in the personal realm, being easily findable online might not be desirable, for those looking to share their expertise, skills, and professional information, a well-cultivated online presence can have multiple benefits. Many search engines see these resources as important, so they are often boosted higher in results lists than comments on blogs or other smaller mentions, ultimately making it easier to reduce the importance of less relevant online information. Taking steps to establish accounts and upload and share professional information can help improve the findability of professional contact information, and even make it easier for others to find and share one's work. It may take some time for various search engines to index the new information, though, and it is a good practice to continue to update online profiles and periodically monitor what appears in one's search results.

\section{References}

boyd, d. (2014), It's Complicated, available at http://www.danah.org/books/ltsComplicated.pdf (accessed 22 July 2014).

\section{Further reading}

Meyers, K. (2013), "Manage Your Digital Identity | Gradhacker @insidehighered", available at http://www.insidehighered.com/blogs/gradhacker/manage-your-digital-identity (accessed 21 July 2014).

Konkiel, S. (2014), "7 tips to supercharge your academic Linkedln profile", available at http://blog.impactstory.org/7-tips-to-supercharge-your-academic-linkedin-profile/ (accessed 21 July 2014).

Amanda Izenstark (amanda@uri.edu) is Reference \& Instructional Design Librarian at the University Libraries, University of Rhode Island, Kingston, RI, USA. 